\title{
Assessment of Renal Function in Egyptian HCV Patients Treated with Combination Therapy of Sofosbuvir and Daclatasvir
}

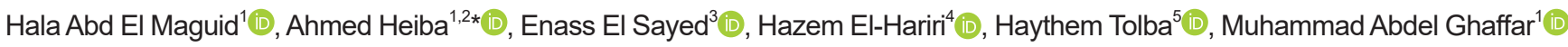 \\ ${ }^{1}$ Department of Gastroenterology and Infectious Diseases, Ahmed Maher Teaching Hospital, Cairo, Egypt; ${ }^{2}$ Department of \\ Internal Medicine, National Research Centre, El-Buhouth St., Dokki, Cairo, Egypt; ${ }^{3}$ Department of Nephrology, Ahmed Maher \\ Teaching Hospital, Cairo, Egypt; ${ }^{4}$ Department of Community Medicine, National Research Centre, El-Buhouth St., Dokki, Cairo, \\ Egypt; ${ }^{5}$ Department of Nephrology, National Institute of Nephrology and Urology, Cairo, Egypt
}

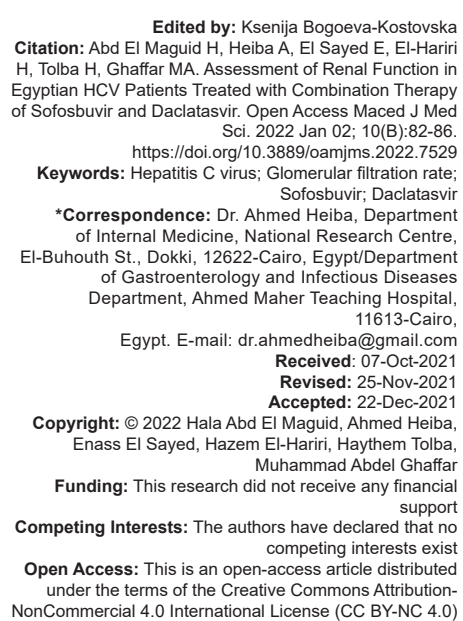

\section{Abstract}

BACKGROUND: According to the most recent Egyptian demographic health census, the estimated Hepatitis $\mathrm{C}$ virus (HCV) prevalence in the 15-59 age range was $14.7 \%$. Globally, the incidence of renal impairment in HCV-positive individuals is $40 \%$ higher than in HCV-negative patients. HCV-induced renal impairment can range from mild-tosevere, and it frequently complicates the treatment outcome of HCV infection.

AIM: This study aimed to explore the changes in renal function in Egyptian HCV patients treated with a combination of Sofosbuvir (SOF) and Daclatasvir (DCV).

METHODOLOGY: Six hundred and eleven chronic HCV patients treated with SOF-DCV were enrolled. Patients were classified into three groups according to their baseline renal function: unimpaired group (estimated glomerula filtration rate $\left[\right.$ eGFR] $\geq 90 \mathrm{ml} / \mathrm{min} / 1.73 \mathrm{~m}^{2}$ ), mildly impaired group (eGFR of $\geq 60-89 \mathrm{ml} / \mathrm{min} / 1.73 \mathrm{~m}^{2}$ ), and moderately impaired group (eGFR of $\geq 30-59 \mathrm{ml} / \mathrm{min} / 1.73 \mathrm{~m}^{2}$ ). Every month during treatment and at 24 weeks after treatment (sustained virological response 24), the eGFR level was evaluated.

RESULTS: Our findings indicated that the eGFR level was significantly increased $(p<0.001)$ in all groups during the treatment but subsequent decline $(p<0.001)$ in all groups was documented after 6 months of treatment. Multivariate analysis identified baseline renal impairment $\left(<90 \mathrm{ml} / \mathrm{min} / 1.73 \mathrm{~m}^{2}, \mathrm{p}<0.001\right)$ and baseline anemia $(p<0.001)$ as independent risk factors for renal function deterioration at the end of treatment.

CONCLUSION: Clinical physicians should closely monitor renal function in patients treated with SOF-DCV. Furthermore, anemia therapy prior to SOF-DCV treatment should be recommended.

\section{Introduction}

Hepatitis C virus (HCV) infection is one of the most common causes of chronic liver disease worldwide, with approximately 130-150 million infected patients, of whom $15-30 \%$ develop cirrhosis with $3-5 \%$ of annual risk for hepatocellular carcinoma. In Egypt, according to the last demographic health survey in Egypt, An estimated HCV prevalence was $14.7 \%$ among the $15-59$ years age group. Accordingly, Egypt has the highest HCV prevalence in the world. Globally, the incidence of renal impairment is $40 \%$ higher in HCV-positive patients compared to $\mathrm{HCV}$ negative [1], [2], [3]. HCV-induced renal impairment ranges from mild to end-stage renal disease, and it commonly complicates the treatment outcome of $\mathrm{HCV}$ infection. With the sustained virological response (SVR) rate that exceeds $95 \%$, sofosbuvir (SOF) and daclatasvir (DCV) have become the main line of therapy adopted by the national hepatitis $C$ treatment program in Egypt [4]. SOF and DCV are generally well-tolerated and reported a few adverse effects, including fatigue, nausea, headache, and insomnia. SOF is eliminated through the kidney, and its concentrations increase in patients with severe renal dysfunction. These drug levels in patients who pose estimated glomerular filtration rate (eGFR( $\geq 30 \mathrm{ml} / \mathrm{min} / 1.73 \mathrm{~m}^{2}$ is similar to those in people with normal renal function [5]. Accordingly, Lim and Ahn reported that these drugs can be utilized without dosage modifications in moderately impaired renal function. Few studies have investigated the long-term renal outcomes after treatment with direct-acting antivirals [6]. The present study aimed to explore the changes in renal function in $\mathrm{HCV}$ patients treated with SOF-DCV combination through measures eGFR levels every month during the treatment and after 24 weeks of treatment (SVR24). 


\section{Methodology}

\section{Patients and study design}

In this retrospective cohort study carried out in a single hospital serving a low-income community in Cairo, Egypt, all patients admitted to the Ahmad Maher Teaching Hospital with HCV between January 2018 and December 2019 were examined. HCV infection has been diagnosed dependent on clinical manifestations and a positive consequence of real-time PCR for blood specimens. The ethical committee of the General Organization of Teaching Hospitals and Institutes in Egypt has endorsed this research (GOTHI; IRB number HAM00104). The study was in compliance with the Helsinki Declaration. Six hundred and eleven HCV patients who were treated with SOF-DCV combination therapy and met the following criteria were enrolled in the present study: (1) infected with HCV; (2) negative for hepatitis B virus, human immunodeficiency virus and cytomegalovirus; (3) no severe renal function impairment (eGFR $<30 \mathrm{ml} / \mathrm{min} / 1.73 \mathrm{~m}^{2}$ ) and end-stage renal disease; (4) no pregnancy; (5) no alcohol use; (6) no malignancy; (7) no hypertensive patients with renal impairment; (8) Patients with controlled diabetes mellitus were included; (9) SOF-DCV combination therapy prescribed according to the recommendation of the recent guidelines [5]. A total of 611 patients were treated with SOF, (400 mg/day)/DCV, (60 mg/day) for 12 weeks ending with SVR at 24 weeks post-treatment (SVR24).

\section{Clinical data}

The medical records of all patients were manually reviewed to determine eligibility based on the previous criteria. Baseline and follow-up analysis including complete blood count, liver enzymes, and serum creatinine was recorded by the outpatient department at baseline (initiation of treatment), at the end of first and second month of treatment, at end of treatment (EOT) and at 24 weeks after treatment, ending with undetected HCV-RNA quantitative PCR (SVR24). According to the World Health Organization criteria, anemia was defined as $\mathrm{Hb}<13 \mathrm{~g} / \mathrm{dL}$ in men or $\mathrm{Hb}<12 \mathrm{~g} / \mathrm{dL}$ in women [7]. eGFR was calculated using the Cockraft-Gault formula [8], [9]. Patients were stratified into three groups according to their baseline renal function: unimpaired (eGFR $\geq 90 \mathrm{~mL} / \mathrm{min} / 1.73 \mathrm{~m}^{2}$ ), mildly impaired (eGFR of $\geq 60-89 \mathrm{~mL} / \mathrm{min} / 1.73 \mathrm{~m}^{2}$ ), and moderately impaired (eGFR of $\geq 30-59 \mathrm{~mL} / \mathrm{min} / 1.73 \mathrm{~m}^{2}$ ). Renal function progression was defined as a change in the eGFR category combined with a minimal percentage of decrease in eGFR by $25 \%$ or greater [10].

\section{Statistical analysis}

Data are presented as means \pm SD or proportions. The differences in continuous and categorical variables across groups were assessed using $t$-test, ANOVA and Chi-square, as appropriate. Changes in eGFR from baseline to SVR24 were analyzed using the repeated-measures ANOVA. To identify factors associated with renal function deterioration multivariate logistic regression was used. $p<0.05$ was considered as statistically significant. Statistical analysis was performed using SPSS 13.0.

\section{Results}

A total of 611 individuals were treated at Ahmed Maher Teaching Hospital and met the study's inclusion criteria. They were all given the SOF-based directacting antivirals SOF and DCV. Overall, $73.6 \%$ of the individuals were male, $6.9 \%$ were cirrhotic, and $22.9 \%$ had type-2 diabetes (DM). According to their baseline renal function and eGFR, all patients were categorized into three groups: $69 \%(n=422)$ had unimpaired renal function (eGFR 116. $\left.25 \mathrm{ml} / \mathrm{min} / 1.73 \mathrm{~m}^{2}\right), 27 \%(\mathrm{n}=164)$ had mild impairment (eGFR $76.89 \mathrm{ml} / \mathrm{min} / 1.73 \mathrm{~m}^{2}$; CKD stage II), and $4 \%(n=25)$ had moderate impairment (eGFR $55.14 \mathrm{ml} / \mathrm{min} / 1.73 \mathrm{~m}^{2}$; CKD stage III). Patients with moderate renal impairment were older than those in the other groups, and the unimpaired group had greater ALT and platelet levels (Table 1). Following that, there was a considerable drop in eGFR from baseline, $1^{\text {st }}$ and the $2^{\text {nd }}$ month to SVR24, and EOT to SVR24 (Figure 1).

Table 1: Baseline characteristics of the study population

\begin{tabular}{|c|c|c|c|c|}
\hline Variables $^{1}$ & Unimpaired group $(n=422)$ & Mild group $(n=164)$ & Moderate group $(n=25)$ & $\mathrm{p}$-value \\
\hline Age, years & $51.52 \pm 11.98$ & $62.85 \pm 8.61$ & $67.44 \pm 8.66$ & 0.01 \\
\hline Male, $\mathrm{n}(\%)$ & $314(74.41)$ & $119(72.56)$ & $17(68)$ & 0.73 \\
\hline Diabetes mellitus, $n(\%)$ & $93(22.04)$ & $41(25)$ & $6(24)$ & 0.74 \\
\hline Cirrhosis, n (\%) & $31(7.35)$ & $8(4.88)$ & $3(12)$ & 0.35 \\
\hline INR & $1.06 \pm 0.1$ & $1.05 \pm 0.1$ & $1.06 \pm 0.1$ & 0.87 \\
\hline Total bilirubin (mg/dl) & $0.56 \pm 0.22$ & $0.59 \pm 0.23$ & $0.53 \pm 0.21$ & 0.30 \\
\hline Serum Albumin & $4.14 \pm 0.39$ & $4.13 \pm 0.41$ & $4.06 \pm 0.36$ & 0.65 \\
\hline AST (U/L) & $43.54 \pm 31.48$ & $38.85 \pm 24.53$ & $53.4 \pm 40.88$ & 0.05 \\
\hline ALT (U/L) & $49.32 \pm 36.54$ & $41.27 \pm 27.52$ & $41.92 \pm 31.75$ & 0.03 \\
\hline Hemoglobin (g/dl) & $13.99 \pm 1.66$ & $13.98 \pm 1.38$ & $13.69 \pm 1.28$ & 0.65 \\
\hline Anemia, n (\%) & $91(21.56)$ & $31(18.9)$ & $6(24)$ & 0.72 \\
\hline Platelets $* 10^{3} / \mu \mathrm{L}$ & $268 \pm 80$ & $247 \pm 72$ & $233 \pm 62$ & 0.01 \\
\hline TLC * $10^{3} / \mu \mathrm{L}$ & $6.69 \pm 1.77$ & $6.56 \pm 1.73$ & $6.31 \pm 1.71$ & 0.46 \\
\hline Serum creatinine (mg/dl) & $0.89 \pm 0.14$ & $1.03 \pm 0.13$ & $1.14 \pm 0.14$ & 0.01 \\
\hline eGFR $\left(\mathrm{ml} / \mathrm{min} / 1.73 \mathrm{~m}^{2}\right)$ & 116. $25 \pm 22.95$ & $76.89 \pm 7.65$ & $55.14 \pm 4.22$ & 0.01 \\
\hline
\end{tabular}




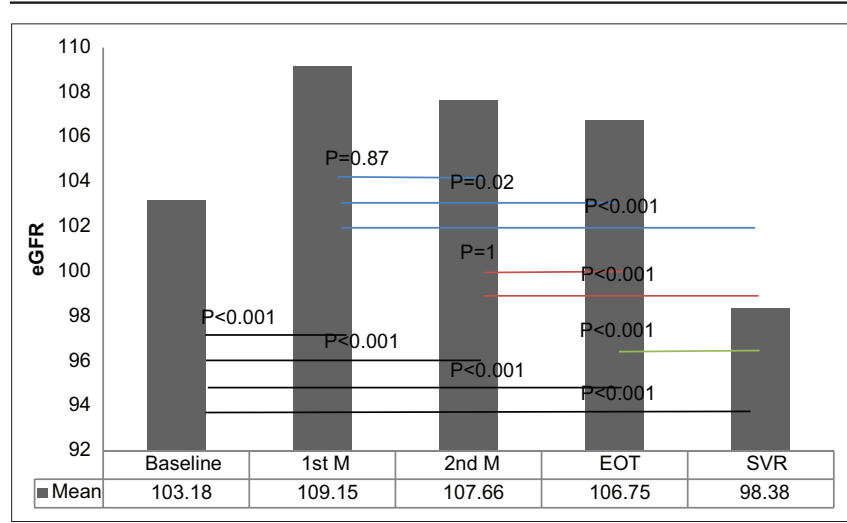

Figure 1: Estimated glomerular filtration rate (eGFR) comparison among all patients Using ANOVA with repeated measures. A bar chart with bars represents mean levels of the eGFR till 24 weeks after treatment (SVR24). A significant increase in eGFR from baseline to the end of first and second month and to the EOT, and a significant decline in eGFR from baseline to SVR24 are representing in black lines with their corresponding $p$ values. While blue lines represent the decline from $1^{\text {st }}$ month to $2^{\text {nd }}$ month, EOT and SVR24 with their $p$ values. The red lines represent the decline in eGFR from $2^{\text {nd }}$ month to EOT and SVR24, and the green line represents the significant decline from EOT to SVR24

The graph depicts the mean eGFR levels from baseline to SVR24 (Figure 2). The pattern of eGFR rise is similar for all patients, although it tends to decrease steadily during the SVR 24 period. There was a substantial rise in eGFR from baseline to EOT $(p=0.001)$ and a significant drop from baseline to SVR $(p=0.001)$ and from EOT to SVR $(p=0.001)$ in the unimpaired group. In the mildly impaired renal function group, eGFR from baseline to EOT $(p=0.001)$. On the contrary, there is a substantial decrease in eGFR from baseline to SVR $(p=0.02)$ and EOT to SVR ( $p$ $=0.001)$. In the moderately impaired renal function group, there was no significant decrease in eGFR from baseline to EOT $(p=1)$, a significant decrease from baseline to SVR $(p=0.12)$, and a considerable decline from EOT to SVR $(p<0.001)$

Renal function deterioration was defined as a change in the eGFR category with a $25 \%$ drop in eGFR from baseline to EOT and SVR24. At SVR24,

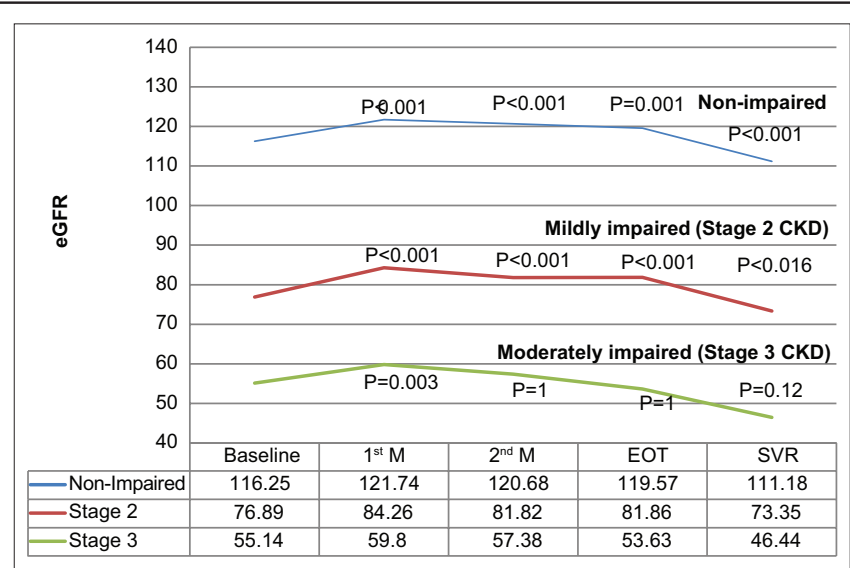

Figure 2: eGFR comparison within renal impairment subgroups using ANOVA with repeated measures. Each trendline represents the mean eGFR value for that subgroup from baseline to SVR24, with the mean value shown in the underlying table as well. The represented $p$ value indicates pairwise comparison from baseline to that time where $p$ value is shown adjacent

33 patients (5.4\%) showed renal function impairment; out of these, $10(2.4 \%)$ were in the unimpaired group, $15(9.1 \%)$ in the mildly impaired group, and $8(32 \%)$ in the significantly impaired group $(p=0.001)$. According to univariate analysis, baseline factors such as mild and moderate renal impairment $(p=$ $0.001)$, anemic patients $(p=0.001)$, older age $(p=$ $0.03)$, and platelet level $(p=0.001)$ were significant predictors of renal function degradation at SVR24. For multivariate analysis, any variables with a $p<$ 0.2 were included. Baseline renal impairment ( $p$ $=0.001)$ and baseline anemia patients $(p=0.001)$ were identified as independent risk variables for renal function deterioration at EOT and SVR24, according to multivariate analysis (Tables 2 and 3 ). In addition, no patients with cirrhosis experienced additional worsening of renal function from EOT to SVR24. However, when comparing renal function degradation from EOT to SVR24 in both groups, this was not significant (Table 4).

Table 2: Univariate and multivariate analysis of predictive factors for renal function deterioration at EOT

\begin{tabular}{|c|c|c|c|c|}
\hline Variables $^{2}$ & No Deterioration (595 pts) & Deterioration (16 pts) & Univariate P-value & Multivariate P-value \\
\hline \multicolumn{5}{|l|}{ Baseline kidney impairment, n (\%) } \\
\hline Non-impaired & $417(98.8)$ & $5(1.2)$ & & \\
\hline Mild-impairment & $153(93.3)$ & $11(6.7)$ & & \\
\hline Moderate-impairment & $25(100)$ & $0(0)$ & 0.002 & 0.002 \\
\hline \multicolumn{5}{|l|}{ Diabetes mellitus, $n(\%)$} \\
\hline No & $459(97.5)$ & $12(2.5)$ & & \\
\hline Yes & $136(97.1)$ & $4(2.9)$ & 0.84 & \\
\hline \multicolumn{5}{|l|}{ Liver cirrhosis, n (\%) } \\
\hline No & $556(97.7)$ & $13(2.3)$ & & \\
\hline Yes & 39 (92.9) & $3(7.1)$ & 0.057 & 0.054 \\
\hline \multicolumn{5}{|l|}{ Anemia, n (\%) } \\
\hline No & $477(98.8)$ & $6(1.2)$ & & \\
\hline Yes & $118(92.2)$ & $10(7.8)$ & 0.0003 & 0.0003 \\
\hline Age, years & $55.2 \pm 12.4$ & $55.56 \pm 12.5$ & 0.909 & \\
\hline Body weight, $\mathrm{Kg}$ & $82.69 \pm 10.28$ & $85.62 \pm 9.2$ & 0.259 & \\
\hline Baseline INR & $1.06 \pm 0.1$ & $1.05 \pm 0.1$ & 0.873 & \\
\hline Baseline total bilirubin $(\mathrm{mg} / \mathrm{dl})$ & $0.56 \pm 0.22$ & $0.62 \pm 0.22$ & 0.283 & \\
\hline Baseline serum Albumin (g/dl) & $4.13 \pm 0.39$ & $4.14 \pm 0.51$ & 0.925 & \\
\hline Baseline AST level (U/L) & $42.65 \pm 30.46$ & $44.00 \pm 25.68$ & 0.860 & \\
\hline Baseline ALT level (U/L) & $46.73 \pm 34.24$ & $51.5 \pm 37.55$ & 0.584 & \\
\hline Baseline TLC level $\left({ }^{*} 10^{3} / \mathrm{mm}^{3}\right)$ & $6.65 \pm 1.75$ & $6.13 \pm 1.94$ & 0.242 & \\
\hline Baseline platelets level $\left({ }^{*} 10^{3} / \mathrm{mm}^{3}\right)$ & $262 \pm 78$ & $225 \pm 50)$ & 0.062 & 0.155 \\
\hline
\end{tabular}


Table 3: Univariate and multivariate analysis of predictive factors for renal function deterioration at SVR24

\begin{tabular}{|c|c|c|c|c|}
\hline Variables $^{3}$ & No Deterioration (578 pts) & Deterioration (33 pts) & Univariate P-value & Multivariate P-value \\
\hline \multicolumn{5}{|l|}{ Baseline kidney impairment, $\mathrm{n}(\%)$} \\
\hline Non-impaired & $412(97.6)$ & $10(2.4)$ & & \\
\hline Mild-impairment & $149(90.9)$ & $15(9.1)$ & & \\
\hline Moderate-impairment & $17(68)$ & $8(32)$ & $<0.001$ & $<0.001$ \\
\hline \multicolumn{5}{|l|}{ Diabetes mellitus, $n(\%)$} \\
\hline No & $442(93.8)$ & $29(6.2)$ & & \\
\hline Yes & $136(97.1)$ & $4(2.9)$ & 0.14 & 0.18 \\
\hline \multicolumn{5}{|l|}{ Liver Cirrhosis, n (\%) } \\
\hline No & $539(94.7)$ & $30(5.3)$ & & \\
\hline Yes & $39(92.9)$ & $3(7.1)$ & 0.72 & \\
\hline \multicolumn{5}{|l|}{ Anemia, n (\%) } \\
\hline No & $467(96.7)$ & $16(3.3)$ & & \\
\hline Yes & $111(86.7)$ & $17(13.3)$ & $<0.001$ & $<0.001$ \\
\hline Age, years & $54.9 \pm 12.3$ & $59.8 \pm 12.5$ & 0.03 & 0.7 \\
\hline Body weight, $\mathrm{Kg}$ & $82.9 \pm 10.2$ & $80.8 \pm 11.8$ & 0.25 & \\
\hline Baseline INR & $1.1 \pm 0.1$ & $1.1 \pm 0.1$ & 0.9 & \\
\hline Baseline total bilirubin (mg/dl) & $0.6 \pm 0.2$ & $0.6 \pm 0.2$ & 0.86 & \\
\hline Baseline serum Albumin (g/dl) & $4.1 \pm 0.4$ & $4.2 \pm 0.5$ & 0.2 & \\
\hline Baseline AST level & $42.3 \pm 30$ & $48.5 \pm 36.1$ & 0.26 & \\
\hline Baseline ALT level & $46.9 \pm 34.2$ & $46.5 \pm 36.7$ & 0.9 & \\
\hline Baseline TLC level $\left({ }^{*} 10^{3} / \mathrm{mm}^{3}\right)$ & $6.7 \pm 1.7$ & $6.2 \pm 1.8$ & 0.15 & 0.44 \\
\hline Baseline Platelets level $\left.{ }^{*} 10^{3} / \mathrm{mm}^{3}\right)$ & $263 \pm 79$ & $225 \pm 50$ & $<0.001$ & 0.56 \\
\hline
\end{tabular}

\section{Discussion}

This study revealed a significant drop in eGFR at SVR24 even in participants with normal renal function at the start. Chiu et al. [11] reported the effect of SOF-based regimens on SVR24 recently, demonstrating a drop in eGFR from SVR12 to SVR24 and SVR48 in their patients. In contrast, other studies have shown that HCV cure is associated with a considerable improvement in eGFR post-treatment [12], [13]. Furthermore, Chiu et al. [11] observed an initial reduction in eGFR toward EOT, followed by a transient spike at SVR12, followed by a further decline in eGFR between SVR24 and SVR48 [11], [14]. The current study found that eGFR improved significantly over the first few months of DAA treatment. Patients with unimpaired or mild renal impairment continued to demonstrate a substantial improvement in eGFR until EOT, but those with severe renal impairment had a non-significant decline in eGFR. The initial improvement in renal functions observed in this study, as well as those observed by Chiu et al. [11], at SVR12, can be explained by HCV clearance with the elimination of their harmful effect on renal tissues, whereas subsequent eGFR decline in both studies should raise concerns about the renal safety profile of SOF-based regimens and the effect of DAA therapy on proteinuria should be evaluated.

Table 4: Comparing the renal function deterioration between Cirrhotic and non-cirrhotic groups

\begin{tabular}{lllll}
\hline Groups & No deterioration & Deterioration & $\%$ & $\mathrm{p}$-value \\
\hline Non-Cirrhotic, $\mathrm{n}$ & 552 & 17 & $93.10 \%$ & \\
Cirrhotic, $\mathrm{n}$ & 42 & 0 & $6.90 \%$ & $\mathrm{p}=0.5$ \\
\hline
\end{tabular}

Another possible explanation for the long-term eGFR reduction after SOF-DCV therapy is an increase in muscle mass in cured HCV patients [15], [16]. This study found a practically significant decrease in eGFR among cirrhotic patients at EOT $(p=0.054)$, but no difference at SVR24 $(p=0.72)$. This quicker reduction in eGFR in cirrhotics (at EOT) compared to non-cirrhotics (at SVR24) could be related to an improvement in their muscle mass following $\mathrm{HCV}$ eradication.

Assessment of tubular damage extent and its effect on the GFR by measuring the neutrophil gelatinase-associated lipocalin and cystatin C-based may be more relevant to assessing renal function, particularly in cirrhotic patients [17], [18]. Renal function worsening was defined as a drop in eGFR of more than $25 \%$ from baseline to EOT and SVR24. According to multivariate analysis, baseline renal impairment and baseline anemia were indicative of renal function decline at SVR24. Our findings are fall in with other previously published reports [19], [20]; that found decreasing renal function was more likely in intermediate renal impairment $(32 \%)$ than in mild impairment (9.1\%).

\section{Conclusion}

Treatment of patients with renal impairment with SOF-based regimens necessitates continuous close monitoring. In addition, prior to SOF-DCV therapy, anemia should be corrected and additional long-term studies with various DAA regimens are still needed.

\section{Limitations}

The study has certain drawbacks. It is a retrospective study, and the effect of DAA therapy on proteinuria was not studied because the majority of patients were not evaluated for proteinuria. Finally, individuals who did not receive or failed the SOF-DCV regimen were excluded from the trial. 


\section{Acknowledgments}

The authors thank the members of Ahmed Maher Teaching Hospital for their support in this study.

\section{Authors' Contributions}

$\mathrm{HM}$ and $\mathrm{AH}$ were involved in the conception and design of the study. EE and HT involved in data collection. HE involved in data analysis and methodology. AH involved in writing the article and revising it critically for important intellectual content. MM involved in final reviewing and approval the version for submission.

\section{References}

1. Li M, Wang P, Yang C, Jiang W, Wei X, Mu X, et al. A systematic review and meta-analysis: Does hepatitis $C$ virus infection predispose to the development of chronic kidney disease? Oncotarget. 2016;8(6):10692-702. https://doi.org/10.18632/ oncotarget.12896

PMid:27793016

2. Barsoum RS. Hepatitis $C$ virus: From entry to renal injury-facts and potentials. Nephrol Dial Transplant. 2007;22(7):1840-8. https://doi.org/10.1093/ndt/gfm205

\section{PMid: 17478492}

3. Elgharably A, Gomaa AI, Crossey MM, Norsworthy PJ, Waked I, Taylor-Robinson SD. Hepatitis C in Egypt past, present, and future. Int J Gen Med. 2016;10:1-6. https://doi.org/10.2147/ IJGM.S119301

PMid:28053553

4. Omar H, El Akel W, Elbaz T, El Kassas M, Elsaeed K, El Shazly $\mathrm{H}$, et al. Generic daclatasvir plus sofosbuvir, with or without ribavirin, in treatment of chronic hepatitis C: Real-world results from 18378 patients in Egypt. Aliment Pharmacol Ther. 2018;47(3):421-31. https://doi.org/10.1111/apt.14428 PMid:29193226

5. Glead Siences Inc. Highlights of Prescribing Information. Available from: chrome-extension:// efaidnbmnnnibpcajpcglclefindmkaj/viewer. html?pdfurl=https \% 3A\%2F\%2Fwww.gilead.com $\% 2 \mathrm{~F} \sim 2 \mathrm{Fmedia} \% 2 \mathrm{Ffiles} \% 2 \mathrm{Fpdfs} \% 2 \mathrm{Fmedici}$ nes $\% 2$ Fliver-disease $\% 2 \mathrm{Fsovaldi} \% 2 \mathrm{Fsovaldi}$ pi.pdf\&clen $=641835 \&$ chunk $=$ true

6. Lim TS, Ahn SH. Use of sofosbuvir in chronic kidney disease: Is it necessary? Clin Mol Hepatol. 2017;23:308-10. https://doi. org/10.3350/cmh.2017.0109 PMid:28948751

7. DeMaeyer E, Adiels-Tegman M. The prevalence of anaemia in the world. World Health Stat Q. 1985;38(3):302-16. PMid:3878044

8. Cockcroft DW, Gault MH. Prediction of creatinine clearance from serum creatinine. Nephron. 1976;16(1):31-41. https://doi. org/10.1159/000180580

\section{PMid:1244564}

9. Sanusi AA, Akinsola A, Ajayi AA. Creatinine clearance estimation from serum creatinine values: Evaluation and comparison of five prediction formulae in Nigerian patients. Afr J Med Med Sci. 2000;29(1):7-11.

PMid:11379474

10. Fraser SD, Blakeman T. Chronic kidney disease: Identification and management in primary care. Pragmatic Obs Res. 2016;7:21-32. https://doi.org/10.2147/POR.S97310 PMid:27822135

11. Chiu SM, Tsai MC, Lin CY, Chen $\mathrm{CH}$, Lu SN, Hung $\mathrm{CH}$, et al Serial changes of renal function after directly acting antivirals treatment for chronic hepatitis C: A 1-year follow-up study after treatment. PLoS One. 2020;15(4):e0231102. https://doi. org/10.1371/journal.pone.0231102 PMid:32287280

12. Sise ME, Backman E, Ortiz GA, Hundemer GL, Ufere NN Chute DF, et al. Effect of sofosbuvir-based hepatitis $C$ virus therapy on kidney function in patients with CKD. Clin J Am Soc Nephrol. 2017;12(10):1615-23. https://doi.org/10.2215/ CJN.02510317 PMid:28882857

13. Faisal N, Bilodeau M, Aljudaibi B, Hirch G, Yoshida EM, Hussaini $\mathrm{T}$, et al. Impact of sofosbuvir-based regimens for the treatment of hepatitis $C$ after liver transplant on renal function: Results of a Canadian national retrospective study. Exp Clin Transplant. 2019;17(1):59-63. https://doi.org/10.6002/ ect.2017.0201

PMid:29619910

14. Tsai MC, Lin CY, Hung CH, Lu SN, Tung SY, Chien RN, et al. Evolution of renal function under direct-acting antivirals treatment for chronic hepatitis C: A real-world experience. J Viral Hepat. 2019;26(12):1404-12. https://doi.org/10.1111/jvh.13193 PMid:31433885

15. Perrone RD, Madias NE, Levey AS. Serum creatinine as an index of renal function: New insights into old concepts. Clin Chem. 1992;38(10):1933-53.

PMid:1394976

16. Sugimoto R, Iwasa M, Hara N, Tamai Y, Yoshikawa K, Ogura S et al. Changes in liver function and body composition by directacting antiviral therapy for hepatitis $\mathrm{C}$ virus infection. Hepatol Res. 2018;48:337-44. https://doi.org/10.1111/hepr.12999 PMid:29115717

17. Yoo JJ, Kim SG, Kim YS, Lee B, Lee MH, Jeong SW, et al. Estimation of renal function in patients with liver cirrhosis: Impact of muscle mass and sex. J Hepatol. 2019;70(5):847-54 https://doi.org/10.1016/j.jhep.2018.12.030 PMid:30630010

18. Haase $M$, Bellomo $R$, Devarajan $P, M a ~ Q$, Bennett MR, Möckel $M$, et al. Novel biomarkers early predict the severity of acute kidney injury after cardiac surgery in adults. Ann Thorac Surg. 2009;88(1):124-30. https://doi.org/10.1016/j. athoracsur.2009.04.023 PMid:19559209

19. Shin HP, Park JA, Burman B, Kozarek RA, Siddique A. Efficacy and safety of sofosbuvir-based regimens for treatment in chronic hepatitis $\mathrm{C}$ genotype 1 patients with moderately impaired renal function. Clin Mol Hepatol. 2017;23(4):316-22. https://doi. org $/ 10.3350 / \mathrm{cmh} .2016 .0087$

PMid:28827512

20. Saxena V, Koraishy FM, Sise ME, Lim JK, Schmidt M, Chung RT, et al. Safety and efficacy of sofosbuvir-containing regimens in hepatitis C-infected patients with impaired renal function. Liver Int. 2016;36(6):807-16. https://doi.org/10.1111/liv.13102 PMid:26923436 